\title{
A santidade no discurso: a construção de uma identidade missionária jesuíta no século XVII
}

Sanctity the discourse: the construction of a jesuit missionary identity in the XVIIth. century

Camila Corrêa e Silva de Freitas*

\section{Resumo}

A publicação de uma crônica e de duas biografias devotas sobre membros da província jesuítica brasileira entre as décadas de 1650 e 1670 pelo padre Simão de Vasconcelos está articulada à defesa e legitimação de uma identidade missionária particular e de uma política de atuação própria da Companhia de Jesus no Brasil. Através da análise destes textos de divulgação e glorificação, observamos como elementos do gênero hagiográfico são utilizados pelo autor para caracterizar todos os companheiros de província, e justificar, através de muitos exemplos de santidade e virtudes exemplares, uma política missionária baseada na tutela civil e religiosa dos indígenas. Ao analisarmos tais discursos inseridos em seu contexto histórico de produção, torna-se possível compreender que Simão de Vasconcelos buscava intervir nos principais debates de sua época através de suas publicações.

Palavras Chave: América Portuguesa, Companhia de Jesus, discurso político, santidade, identidade missionária.

\begin{abstract}
The publication of a chronic and two hagiographic-biographical texts of members of the Brazilian Jesuit province between the decades of 1650 and 1670 by father Simão de Vasconcelos is hinged to the defense and legitimization of a particular missionary identity and an specific policy of the Society of Jesus in Brazil. Through the analysis of these glorification texts, we observe how elements of the hagiographical genre are used by the author to characterize all the companions of the province, and justify, through many examples of holiness and exemplary virtues, a missionary policy based on religious and civil protection of indigenous people. By analyzing these discourses embedded in its historical context of
\end{abstract}

\footnotetext{
* Universidade de São Paulo (Programa de Pós-Graduação em História Social).
} 
production, it becomes possible to understand that Simão de Vasconcelos sought to step in the key debates of his time through his publications.

Key words: Portuguese America, Society of Jesus, political discourse, sanctity, missionary identity.

Recibido: 12 de junio de 2014

Evaluado: 20 de junio de 2014 
Todos os dias, que nesta forma esteve, correu grande rumor na cidade, $e$ principalmente entre aqueles a quem tinha servido, confessado, aconselhado e curado em suas enfermidades; davam-se os pêsames uns aos outros dizendo geralmente: 'Morre o santo, morre o santo'. Tinha bem que fazer o porteiro em trazer e levar peças várias, que os devotos mandavam tocar em seu corpo, e em pedir coisas de seu fato, de sua letra, e de seus cilícios, que houvessem de servir por relíquias. Uma só sangria lhe fizeram na testa, e todo o sangue desta embeberam os devotos em lenços, que repartiram por relíquia prezada, com que depois foi Deus servido obrar (segundo sua fé) coisas maravilhosas ${ }^{1}$.

É assim que o padre jesuíta Simão de Vasconcelos narra a recepção da notícia da morte de um companheiro na província do Brasil, o padre João de Almeida. Falecido na capitania do Rio de Janeiro em 1653, sua vida e morte foram contadas por Vasconcelos na obra Vida do Padre João de Almeida da Companhia de Jesu, impressa em Lisboa em 1658 , mas escrita provavelmente em 1655, segundo o próprio autor ${ }^{2}$. Alguns anos depois, em 1672, saía da oficina de João da Costa outra biografia, a Vida do Venerável Padre José de Anchieta da Companhia de Jesus, de autoria do mesmo Vasconcelos. Nestas obras, o padre apresenta argumentos claramente favoráveis à canonização dos dois jesuítas, muito bem amarrados em um discurso cronológico de suas vidas. Não se tratam, portanto, de quaisquer biografias, mas da narrativa de "vidas devotas", biografias de caráter hagiográfico ${ }^{3}$.

$\mathrm{Na}$ análise que desenvolveremos nas próximas páginas, buscaremos demonstrar como os discursos histórico-biográficos do padre Vasconcelos procuravam atingir um triplo objetivo: construir a imagem santificada e virtuosa de dois missionários da província jesuítica do Brasil como representantes da excelência de todos os seus membros, para, a partir disto, vincular a consolidação e prosperidade da América Portuguesa à atuação missionária dos padres da Companhia e justificar e defender a política missionária praticada pela Ordem no Brasil desde meados do século XVI.

$\mathrm{Na}$ narrativa de Vasconcelos, percebemos a utilização de elementos tradicionalmente associados à santidade entre os católicos para caracterizar a vida e a morte tanto de Almeida quanto de Anchieta. A realização de milagres através de objetos do suposto santo é um exemplo. Na tradição cristã, o santo era originalmente venerado por ser exemplo de sofrimento excepcional, por ter morrido como e por Cristo, morrido por sua fé. O sentido de santidade era, portanto, associado ao de martírio. Contudo, rapidamente a devoção se estendeu a homens de virtudes exemplares e que realizavam milagres, através dos quais se manifestava o poder de Deus. Imitadores de Cristo na vida e na morte. Os objetos por eles tocados ou usados passaram a ser igualmente

\footnotetext{
${ }^{1}$ BNRJ, Seção de Obras Raras, 45-2-4, Vasconcelos, Vida do Padre João de Almeida da Companhia de Jesus, Lisboa: Oficina Craesbeeckiana, 1658, p.336.

2 “...desde o ano de 1549, até o presente de 1655 em que isto escrevo”. Ibid.:"Prólogo por advertência ao leitor”. Sem paginação.

3 Entendemos por “vidas devotas" ou "biografias devotas" o gênero literário biográfico que se desenvolveu sobremaneira entre os séculos XVI e XVII na Europa sobre as vidas de homens e mulheres que morreram em "odores de santidade", mas que não haviam sido oficialmente reconhecidos como santos pela Igreja Católica Romana, diferenciando-se assim das hagiografias, narrativas biográficas sobre indivíduos já canonizados oficialmente. Ver Gotor, 2004: 63-65.
} 
venerados após sua morte, pois se acreditava que se seus corpos eram santificados, por extensão, também o eram seus objetos ${ }^{4}$.

O registro da vida dessas pessoas, já nos séculos medievais, cumpriu, em parte, a função de fornecer bons exemplos aos cristãos. As “vidas devotas” e as hagiografias, produzidas geralmente por religiosos, serviam de material aos pregadores para a elaboração de seus sermões. Tais escritos chegaram aos séculos XVI e XVII em reedições de obras como a Legenda Áurea, coletânea hagiográfica do século XIII publicada desde então em várias línguas ${ }^{5}$.

Desde o culto aos primeiros mártires cristãos até o século XVI, o reconhecimento público de um santo e o estabelecimento de seu culto ocorriam com certa facilidade. Em geral, por pressão de um grupo de crentes nos atos "maravilhosos" do pretenso santo, os bispos ratificavam e promoviam o culto e o título. Mesmo quando, em 1234, estabeleceu-se que a atribuição do título de santo e a autorização ao culto eram prerrogativas do pontífice, muitos santos locais continuaram aparecendo e granjeando devotos. No entanto, desde então, a Santa Sé constituiu um aparato teológico e jurídico para julgar os casos de santidade ${ }^{6}$.

O século XVI trouxe mudanças significativas para o processo de reconhecimento eclesiástico da santidade e para a escrita das "vidas devotas". As reformas protestantes promoveram ampla contestação à autoridade religiosa da Igreja Católica Romana. As críticas teológicas, litúrgicas e morais se dirigiam também ao culto de santos, uma vez que, para os protestantes, um "santo" recebia tanta graça quanto qualquer outro cristão e, assim como os sacerdotes, não tinha autoridade ou poder algum para mediar a relação entre os fiéis e Deus ${ }^{7}$. Em resposta, o Concílio de Trento afirmou que Cristo era o único redentor e salvador da humanidade, mas também defendeu o papel positivo dos santos como intercessores das causas humanas junto ao poder e vontade divinos. A turbulenta conjuntura de contestação da autoridade religiosa e teológica da Santa Sé resultou em medidas práticas e rigorosas quanto ao reconhecimento da santidade, e consequentemente, em mudanças no registro escrito da vida de pretensos santos ${ }^{8}$.

A partir da segunda metade do século XVI, a Igreja Católica promoveu uma ampla reformulação, de tendência marcantemente centralizadora, dos mecanismos de reconhecimento da santidade e dos processos de canonização e beatificação. Exemplo disto foi a criação da Congregação dos Ritos, em 1588, cujo objetivo era preparar os processos jurídicos das canonizações papais e autenticar as relíquias. As regras tornaram-se cada vez mais complexas e detalhadas e encontraram sua culminância nos decretos do papa Urbano VIII (1623-1644). Entre suas medidas mais relevantes,

\footnotetext{
${ }^{4}$ Woodward,1992: 55-59; Gajano, 1999: 23.

${ }^{5}$ Franco Júnior, 2003: 11-25.

6 Delooz, 1983: 191-192. Em 1234, o papa Gregório IX publicou suas Decretais, uma coleção de leis pontifícias nas quais afirmou a absoluta jurisdição do pontífice romano sobre todas as causas dos santos, tornando essa regra obrigatória para a Igreja universal. Uma vez que os santos eram objeto de devoção para toda a Igreja, só o papa, com sua jurisdição universal, tinha autoridade para canonizá-los; em 1247, a Santa Sé também proibiu a publicação de livros sobre os milagres ou revelações de santos não oficiais, bem como a exposição deles com auréolas. Ver Woodward, 1992: 66-67.

${ }^{7}$ Ibid.: 74 .

${ }^{8}$ Sodano, 1997: 190.
} 
destacaram-se o decreto de 1625 e o breve papal Coelestis Hierusalem cives, de 1634, que proibiram qualquer forma de veneração pública a santos não reconhecidos oficialmente pela Santa Sé, inclusive a publicação de livros sobre milagres ou revelações atribuídas a um suposto santo. Os decretos de Urbano VIII também precisaram os requisitos para a introdução da causa de um santo, como, por exemplo, a prática comprovadamente extraordinária das virtudes teológicas (fé, esperança e caridade) e cardeais (fortaleza, justiça, prudência e temperança), a observância dos votos de pobreza, castidade e obediência, obrigatórios a qualquer religioso, e a existência de uma legítima fama de santidade e milagres. Não por acaso, os processos de canonização encaminhados na Igreja Romana passaram a dar grande valor às testemunhas e aos elementos comprobatórios dos milagres, revelações e profecias atribuídos aos pretensos santos ${ }^{9}$.

A leitura das biografias de João de Almeida e José de Anchieta deixa claro que as regras romanas estiveram no horizonte de escrita de Simão de Vasconcelos. A começar pelas protestações que o autor faz no princípio das obras em cumprimento às determinações papais. Nelas, o padre afirma que os elogios de "santo", feitos ao longo do texto, fundam-se na opinião humana e, por isso, não eram de caráter oficial.

A divisão das obras indica que se tratam de biografias que se pretendem hagiográficas: dos oito livros que compõe a Vida do Padre João de Almeida, quatro são dedicados ao relato de milagres, visões, profecias e revelações atribuídas ao padre, inclusive após a sua morte, além de longas considerações sobre suas virtudes cristãs. Da mesma forma, a maior parte dos sete livros que formam a Vida do Venerável Padre José de Anchieta, ao acompanharem a trajetória cronológica do mesmo como reitor do colégio de São Vicente, provincial e superior da casa do Espírito Santo, detêm-se essencialmente no relato dos diversos casos de profecias, milagres, visões e revelações ocorridas em diferentes pontos da província por onde o padre passara.

O padre Vasconcelos constrói seus protagonistas associando-os a elementos ordinariamente relacionados à santidade desde o medievo europeu, como os milagres e as características post mortem, isto é, a não putrefação da carne, a emanação de odores agradáveis e os poderes curativos de objetos pertencentes ao "santo" morto. Tendo anunciado em diversas passagens das obras que tinha como objetivo contribuir com argumentos para a canonização dos dois jesuítas da Província do Brasil, o autor preocupa-se em apresentar Almeida e Anchieta como figuras exemplares das virtudes e autores de milagres então valorizados pelos tribunais romanos. Temos assim um João de Almeida e um José de Anchieta superlativos em todas as virtudes cristãs: extremamente humildes, profundamente castos, obedientíssimos, desapegados de quaisquer bens materiais, que cuidavam do próximo e não de si e cuja fama de santidade era viva entre todos aqueles que testemunharam suas "maravilhas" nos locais onde eles estiveram. Os episódios das vidas dos dois padres servem a Vasconcelos para demonstrar a prática das mais altas virtudes cristãs junto a índios e portugueses.

Boa parte das curas milagrosas e de outros atos "extraordinários” são relatados sistematicamente em amplos conjuntos de casos que exemplificam as curas, as profecias e revelações testemunhados por moradores, nomeados e localizados no tempo e no espaço, nas vilas e cidades da América Portuguesa. Há um inegável esforço por parte do autor em demonstrar a veracidade da fama de santidade dos dois companheiros de

\footnotetext{
${ }^{9}$ Ibid.: 191-192; Von Pastor, 1938: 9-10.
} 
província. Para isso, Vasconcelos insere testemunhos alegadamente fidedignos, processos jurídicos e documentos da época que ele cita ou reproduz ${ }^{10}$. Parece claro, além de ser declarado pelo autor, que a caracterização dos "santos" jesuítas e a extensa apresentação de casos "maravilhosos" e de inumeráveis testemunhas formam um arcabouço argumentativo pró-canonização, de acordo com os padrões da época.

No entanto, as biografias devotas sobre João de Almeida e José de Anchieta apresentam elementos que nos sugerem que os objetivos do discurso do padre Simão não se limitavam à promoção destes dois companheiros aos altares católicos.

Logo no princípio das duas obras, um elemento curioso chama a atenção. Ao dar início à leitura da "Vida" de João de Almeida, uma longa lista de sessenta e quatro nomes de jesuítas é apresentada no "Prólogo por advertência ao leitor". A este Breve Catálogo dos Varões Insignes da Companhia de Jesus que floresceram em Virtude na Província do Brasil, como o intitula o padre Vasconcelos, e que começa com Manoel da Nóbrega e termina com Almeida, precede um texto explicativo. Nele, o autor defende a importância do trabalho de evangelização que os religiosos vinham fazendo entre os gentios e esclarece seus objetivos ao nomear tais "obreiros da fé": dar notícia dos tantos varões virtuosos e exemplares que haviam vivido e trabalhado no Brasil e desenganar alguns “...que erradamente teriam para si estar destituída de Homens Santos esta Província”" ${ }^{11}$.

Em seção introdutória similar da "Vida" de Anchieta, Vasconcelos reafirma a excelência geral dos membros da Província:

Advirto aqui aos leitores, que não é só este grande P.(padre) aquele cujas excelências andam diminutas pelo orbe, senão que são tantos os Varões ilustres que nesta Província acabaram a vida com fama pública de santidade e exemplos raros, que se assim como andam suas notícias despedaçadas por vários autores, houvera nelas a mesma diligência, sairão a luz grandes tomos e histórias tão peregrinas, que puderam ilustrar a Companhia... ${ }^{12}$.

Na Chronica da Companhia de Jesu do Estado do Brasil, a obra mais conhecida do padre Simão, publicada em 1663, cinco anos apenas após a impressão da biografia de Almeida, o autor dá continuidade ao elogio em conjunto e, assim como havia feito em proporções menores na "Vida" de Almeida, apresenta diversas pequenas biografias dos "religiosos varões" da Companhia e de seus "feitos ilustres" na evangelização dos povos do Brasil. Manoel da Nóbrega é o grande herói dessa história, “Apóstolo do Brasil” e exemplo maior das virtudes dos da província brasileira.

Este tipo de discurso encomiástico dos membros da própria província constituía uma forma quase protocolar em obras de religiosos sobre suas próprias ordens ${ }^{13}$. No

\footnotetext{
${ }^{10}$ É possível que Vasconcelos tenha incorporado elementos da escrita crítica das hagiografias idealizada pelos jesuítas bollandistas, como era conhecido um grupo de padres eruditos, liderados por Jean Bolland na Holanda seiscentista, que defendiam a pesquisa crítica das fontes históricas e privilegiavam o documento e o "fato". Ver Certeau, 1982: 267-268.

${ }^{11}$ BNRJ, Seção de Obras Raras, 45-2-4, Vasconcelos, Vida do Padre João de Almeida da Companhia de Jesus, Lisboa: Oficina Craesbeeckiana, 1658, “Prólogo por advertência ao leitor”. Sem paginação.

${ }^{12}$ BNRJ, Seção de Obras Raras, Cofre II, 5, 3, Vasconcelos, Vida do Venerável Padre José de Anchieta da Companhia de Jesus, Lisboa: João da Costa, 1672, "Prólogo ao leitor”. Sem paginação.

13 Santos, 2001: 161.
} 
entanto, parece significativo que, no princípio de biografias que afirmam a santidade de dois jesuítas, este atributo singular, que deveria diferenciá-los dos demais, os iguale aos outros membros da província e acabe por fazê-los representantes do grupo ${ }^{14}$.

Ainda na Chronica, ocupando praticamente todo o quarto livro da mesma, o padre Simão nos conta “... a história notável do martírio insigne dos 40 mártires da Companhia de Jesus do Brasil, Inácio de Azevedo e seus companheiros, com breve suma de suas vidas” ${ }^{15}$. Liderados pelo padre Inácio de Azevedo, que fora provincial e visitador do Brasil (1566-1568), estes trinta e nove homens de fato nunca pisaram em terras brasileiras. Morreram sem terem sequer avistado um monte ou praia da América Portuguesa. Ainda assim, Simão de Vasconcelos narra com detalhes a preparação daqueles padres e irmãos que 'transbordavam' virtudes para vir ao Brasil. Sua trágica morte nas mãos dos calvinistas franceses é contada minuciosamente, enfatizando a crueldade dos "hereges” e o sofrimento dos “soldados de Cristo".

No fim das contas, o que parece importante para Vasconcelos é intitulá-los "mártires da Companhia de Jesus do Brasil", fortalecendo e destacando assim a província brasileira entre as outras províncias jesuíticas espalhadas pelo mundo, incorporando as virtudes e o terrível sacrifício de Azevedo e seus companheiros: “ E tu, ó Companhia de Jesus do Brasil, com razão podes prezar-te de tão insignes filhos, com cujos nobres procedimentos te honraste, e com cujo sangue cresceste"16.

O empenho de Simão não era casual. Santos e mártires do Brasil vinham à luz para buscar seu lugar entre outros já mais conhecidos. Na primeira metade do século XVII formara-se uma espécie de paradigma de missionário jesuíta exemplar ligado às missões do Oriente, fomentado pela publicação de muitas obras de membros da Companhia sobre as missões orientais ${ }^{17}$. Em 1622, Francisco Xavier fora canonizado e, cinco anos depois, três irmãos da Companhia no Japão, mortos em fins do século XVI, foram declarados mártires e beatificados ${ }^{18}$. Assim, não por acaso, elementos comparativos entre os jesuítas do Brasil e os do Oriente, particularmente Francisco Xavier, aparecem com frequência nas duas biografias e na Chronica. Vasconcelos empenha-se em demonstrar as virtuosas atividades e perigos aos quais também estiveram submetidos os companheiros do Brasil, e como em nada ficaram devendo as atividades Manoel da Nóbrega na América em relação ao “Apóstolo da Índia”, Francisco Xavier ${ }^{19}$. Por comparação, o autor buscava divulgar uma província brasileira tão exemplar e gloriosa quanto as do Oriente.

Apesar de pertencerem a gêneros literários diferentes, podemos analisar as duas biografias e a Chronica em conjunto, uma vez que parecem formar uma espécie de genealogia dos muitos exemplos de santidade e virtudes dos membros da província jesuítica brasileira. Desde Nóbrega, passando por Inácio de Azevedo, José de Anchieta

\footnotetext{
${ }^{14}$ Certeau, 1982: 268.

${ }^{15}$ Vasconcelos, 1977, v.2: 150.

${ }^{16}$ Ibid.: 191.

${ }^{17}$ Santos, 2001: 152.

${ }^{18}$ ARSI, Inventário Santi e Beati della Compagnia.

19 "E não somente no Brasil; em Roma, em Portugal, no mundo todo foi conhecida sua santidade; ao menos pela empresa que tomou a seus ombros, igual a de um Xavier: ficando partida entre dois varões apostólicos a conversão da gentilidade do mundo; a Xavier ficou a do Oriente; a Nóbrega a do Ocidente”. Vasconcelos, 1977, v.2: 209.
} 
e João de Almeida, o padre Vasconcelos apresenta nessas três obras um largo painel narrativo para demonstrar como, desde a fundação da missão no Brasil até os seus dias, em meados do século XVII, a santidade e a prática das virtudes caracterizavam seus companheiros $^{20}$.

O discurso altamente elogioso a João de Almeida, José de Anchieta e aos jesuítas da província brasileira em geral é construído, em parte, sobre a atuação missionária dos mesmos.

Se o padre Simão de Vasconcelos dedica aproximadamente metade das páginas da biografia devota sobre João de Almeida ao relato de seus feitos "maravilhosos" e de suas virtudes, os três primeiros livros da obra narram a vida do Almeida missionário. Em sua formação, o padre teria aprendido com a dedicação exemplar e virtuosa de alguns companheiros, cujas missões o autor nos relata longa e detalhadamente por dezenas de páginas. Convivendo com a fome, sede, com os perigos do canibalismo indígena e das guerras entre as tribos, João de Almeida aparece como membro das primeiras gerações de jesuítas do Brasil, plenas em virtudes e que teriam sido bem sucedidas em sua tarefa de catequizar, promover o descimento dos índios do interior, formar aldeias, residências e lhes prover assistência física e espiritual.

Seria larga digressão se houvéramos de ir discorrendo em forma por todos os varões semelhantes que aqui concorreram neste tempo. Basta dizer que foram muitos e insignes todos, e que parece que a mesma Providência Divina de propósito os ajuntava ali, para de muitos tirar um exemplar perfeito, e acabado em todas as virtudes religiosas (em nosso João de Almeida) ${ }^{21}$.

Ativo, incansável, sempre disposto a acudir corpos e almas necessitados, independentemente das dificuldades que se apresentassem, mais do que um simples religioso, o padre Almeida é apresentado como representante da excelência do missionário da Província do Brasil. Nas três grandes missões do padre narradas por Vasconcelos, duas com os índios carijós ou patos (em 1617 e em 1621) e uma com os goitacazes (1619), Almeida é extremamente bem-sucedido em catequizar multidões de índios e trazê-los para o grêmio da Igreja, ainda que não tenha conseguido trazer todos para as aldeias administradas pelos padres.

Na "Vida" de Anchieta, Vasconcelos não se detém tanto no relato das missões do padre. Poucos são os episódios que narram especificamente as atividades de Anchieta junto aos índios, como a catequese, os descimentos do interior, a formação e o funcionamento das aldeias administradas pelos religiosos da Companhia. Quando aparecem, contudo, são sempre narrados de maneira positiva e bem-sucedida e a salvação espiritual dos indígenas é, repetidas vezes, apontada como prioritária para o protagonista. Assim, apesar de não se alongar neste aspecto, é inegável que Simão apresenta Anchieta também como um missionário, sempre zeloso do cuidado espiritual do próximo em suas andanças pela província.

Os "Santos Varões” da província do Brasil, representados nas biografias por Almeida e Anchieta, e protagonistas de vários episódios narrados na Chronica, mais do

\footnotetext{
${ }^{20}$ Santos, 2008: 158-159.

${ }^{21}$ BNRJ, Seção de Obras Raras, 45-2-4, Vasconcelos, Vida do Padre João de Almeida da Companhia de Jesus, Lisboa: Oficina Craesbeeckiana, 1658: 39.
} 
que simplesmente colaborarem para a catequese e cuidado espiritual dos nativos pagãos, teriam implementado e desenvolvido com grande sucesso uma política missionária própria, baseada nos aldeamentos, espaços de civilização e evangelização de nativos trazidos do interior, onde os mesmos estavam sujeitos à moral cristã, às leis do rei e às leis de Deus, educados e tutelados pelos padres da Companhia.

“(...) persuadidos os moradores daquelas brenhas da verdade e serenidade de nossa santa fé, corriam bandos deixando seus sertões para o lugar aonde moravam os padres.

(...) Começaram a ser catequizados, fazendo-lhes práticas ora o mestre, ora os mais destros e eloquentes discípulos na língua brasílica, e era grande o gosto de José, vendo o conceito que fazia das coisas divinas, gente tão bárbara por outra via. Afeavam-lhes os ritos de sua gentilidade, o abuso da carne humana [...]; e tudo ouviam e aprovavam e, o que mais é, admitiam com vontade firme...."22

(...) convenceu aqueles corações, por natureza feros, instruindo-os no conhecimento de Deus e a muitos deles persuadindo-os a deixar a pátria, parentes, comodidades, costumes tão antigos e tudo o que tinham; e irem-se após ele a fazerem-se cristãos e buscar a Igreja de Deus, como com efeito fizeram... ${ }^{23}$.

(...) E quem duvida que o Tapuia mais montanhês, reduzido a trato político, pode tornar a aperfeiçoar o lustre perdido da humana espécie? Muitos vi com meus olhos trazidos do tosco das brenhas, e na aparência uns brutos: $e$ contudo andados os anos, com a criação, e doutrina dos Padres da Companhia, os achei depois tão trocados, que quase não os conhecia ${ }^{24}$.

Através da missionação e da administração dos aldeamentos, Vasconcelos apresenta o trabalho conjunto desenvolvido pelos jesuítas: o da civilização/sujeição e o da conversão, destacando e defendendo como indissociável a atuação religiosa e política dos padres da Companhia na América Portuguesa, uma vez que seriam os aldeamentos que teriam viabilizado o projeto real de ocupação e exploração do território, ao submeterem e incorporarem de maneira produtiva o elemento indígena. Os benefícios de tal política missionária para os portugueses são largamente alardeados tanto nas "Vidas" quanto na Chronica. De fato, Vasconcelos apresenta os missionários como intermediários indispensáveis entre portugueses e indígenas. Através da redução das populações nativas aos aldeamentos gerenciados pelos padres, o padre Simão mostra uma Companhia de Jesus que possibilitava a ocupação do território pelos lusos na medida em que submetia sua população nativa e a tornava proveitosa para a exploração econômica e para a defesa da colônia.

(Os padres) lhes propuseram as conveniências e razões que havia pelas quais era bem que assentassem pazes entre si e os portugueses, recontandolhes as causas urgentes que tinham estes de estarem agravados por serem assaltados, mortos e comidos de sua gente a cada passo em seus caminhos,

\footnotetext{
${ }^{22}$ Vasconcelos, 1953:32-33.

23 BNRJ, Seção de Obras Raras, 45-2-4, Vasconcelos, Vida do Padre João de Almeida da Companhia de Jesus, Lisboa: Oficina Craesbeeckiana, 1658, pp.137-138.

${ }^{24}$ Vasconcelos, 1977, v.1: 118.
} 
indo de paz e desacautelados; contando-lhes casos em particular que eles bem sabiam e não podiam ignorar. E a disto lhes falaram de Deus, da vida eterna e da necessidade que tinham do ir viver entre os portugueses para salvar-se. (...)

(Os índios) assentaram não somente as pazes, mas que viriam morar junto aos portugueses e que poriam suas aldeias em tal paragem que pudessem ser visitados e doutrinados pelos padres. (...) Partiram os padres contentes com suas respostas: deram por bem empregado seus trabalhos e voltando deram novas de todo o sucesso aos moradores do Rio de Janeiro, em cujo serviço iam, que estimaram em muito as pazes e com efeito os goitacazes cumpriram a palavra, vieram a seu tempo e dali em diante houve mais segurança nos caminhos, a custa dos trabalhos destes nossos incansáveis missionários ${ }^{25}$.

Assim sendo, às características mais comuns da santidade católica associadas a João de Almeida e José de Anchieta, Vasconcelos acrescenta a de santos missionários que praticavam sua missão nos aldeamentos. Ao propor o reconhecimento da santidade de Anchieta e de Almeida, condição superior, positiva e excepcional na hierarquia simbólica católica, e apresentá-los enquanto representantes dos missionários da província brasileira, Simão de Vasconcelos não apenas estende os altos elogios dedicados aos biografados a todos os companheiros. Ele defende e legitima a política missionária praticada pela Ordem no Brasil, assentada na dupla tutela, religiosa e civil, dos padres sobre a população indígena aldeada, ao relacioná-la a dois pretensos santos.

A construção discursiva de dois santos jesuítas missionários e de um amplo painel cronológico dos "santos varões em virtudes" da província, em meados do século XVII, não era fortuita. A política de aldeamentos representada pelos religiosos da Companhia se tornara extremamente problemática no Brasil seiscentista. O padre Simão publicou suas obras em uma época em que tanto a dupla tutela sobre os índios estava sendo violentamente questionada nas capitanias, quanto o apoio da Coroa portuguesa, até então consistente através de legislações indigenistas que delegavam aos padres da Companhia a administração espiritual e temporal das aldeias, vacilava ${ }^{26}$.

Quando os primeiros religiosos da Sociedade de Jesus começaram a vir para a América lusa, vieram junto com as primeiras iniciativas de organizar a ocupação portuguesa no território. Em parceria com as autoridades civis e com a Coroa, os padres atuaram no controle da população nativa, que se mostrava em parte hostil e vinha dificultando o estabelecimento dos europeus. Com o aval dos governantes portugueses, através de leis indigenistas, os jesuítas foram incumbidos de catequizar e tutelar os índios catecúmenos em termos religiosos e políticos, o que incluía o controle sobre o uso de sua força de trabalho pelos moradores da América Portuguesa. A formação de unidades administradas pelos padres, os aldeamentos, inicialmente se apresentou como

\footnotetext{
${ }^{25}$ Ibid.: 156-160. O destaque é nosso.

${ }^{26}$ Em 1570, a primeira de uma série de leis e decretos regulatórios sobre a exploração do trabalho indígena e sobre a administração da população nativa aldeada na América Portuguesa foi promulgada, decretando a liberdade dos índios e limitando seu cativeiro a casos específicos considerados legítimos. O decreto destacava três casos: o de "guerra justa", o de resgate ou comutação de pena, e o de necessidade extrema. Desde então até meados do século seguinte, as leis relativas ao assunto em geral designaram aos religiosos da Companhia de Jesus a administração religiosa e civil da população nativa aldeada e a participação nos descimentos de indígenas ao interior. Ver Perrone-Moisés, 1992.
} 
estrategicamente positiva para a ocupação lusitana. Os índios aldeados constituíam uma reserva de mão-de-obra acessível e importante para serviços militares, obras públicas e trabalhos para os moradores. Contudo, a existência de aldeamentos jesuíticos foi se tornando um ponto de tensão ao longo dos anos. Em inícios do século XVII, a combinação da tutela espiritual e da administração temporal da mão-de-obra nativa pelos religiosos já desagradava alguns governantes e moradores da América Portuguesa. O controle temporal das aldeias, atribuído com exclusividade aos padres da Companhia por decretos reais, implicava na dificuldade de acesso aos trabalhadores indígenas, cujos contratos de trabalho com os moradores eram mediados pelos jesuítas. Além disso, a política de aldeamento se articulava à uma política indigenista do governo português que limitava o cativeiro de índios a situações específicas ${ }^{27}$. Este tipo de inserção controlada da população nativa em uma sociedade em construção, como na América Portuguesa, entrou em confronto com o crescimento da população de origem lusa e de suas necessidades materiais, fatores que ampliaram a demanda por mão-de-obra. A procura pela força de trabalho indígena cresceu especialmente em regiões onde a mesma se apresentava como a solução economicamente mais interessante e acessível, como São Vicente e Maranhão. E foi justamente nestas áreas que os missionários da Companhia enfrentaram críticas, ataques violentos e a expulsão, promovida pelos vicentinos, em 1640, e em 1661, no Maranhão.

Os padres jesuítas conseguiram retornar a São Vicente em 1653 por meio de acordos firmados entre os próprios religiosos e as câmaras municipais da capitania. Os desdobramentos do episódio de expulsão do Maranhão, no entanto, apontaram para o enfraquecimento do apoio da Coroa lusa à política missionária baseada na dupla administração dos aldeamentos. Em dezembro de 1663, o rei D. Afonso VI, cujo governo se mostrou desde o início desfavorável aos jesuítas, assinou uma provisão que aboliu a jurisdição temporal dos missionários da Companhia no Estado do Maranhão e Grão-Pará, e permitiu que todas as religiões participassem da jurisdição espiritual dos índios, acabando com o privilégio dos jesuítas; estes também perderam a iniciativa das entradas ao sertão, passada às câmaras municipais, e perderam toda a interferência obrigatória que tinham nas mesmas e nas repartições dos índios ${ }^{28}$.

As tensões e críticas que envolviam as estratégias missionárias dos jesuítas do Brasil em meados do século XVII não se limitavam a estas relacionadas aos moradores da América Portuguesa e ao governo de Portugal. Elas também estavam presentes nas relações entre a província brasileira e o comando romano da Ordem.

Desde fins de século XVI e durante boa parte do século seguinte, o governo geral da Companhia criticou com maior ou menor aspereza os métodos de missionação no Brasil, especialmente no tocante à formação e administração de aldeias indígenas pelos missionários. O envolvimento dos jesuítas em atividades temporais e no controle de um tipo de mão-de-obra largamente utilizado pelos moradores e, consequentemente, em questões políticas, econômicas e militares, deu origem a críticas e tentativas de intervenção na Província pelos Padres Gerais, através de seus visitadores ${ }^{29}$.

De fato, desde o generalato do padre Francisco Borgia (1565-1572), o comando geral da Ordem mostrava-se explicitamente contrário à solução missionária idealizada e

\footnotetext{
${ }^{27}$ Ver nota anterior.

${ }^{28}$ Azevedo, 1992: 299.

${ }^{29}$ Castelnau-L’Estoile e Zeron, 1999.
} 
concretizada por Manoel da Nóbrega e seus companheiros no Brasil. Por decisão do Padre Geral, a combinação da gestão espiritual e temporal jesuítica dos aldeamentos deveria ter sido suprimida já naquela época. A determinação interna do Instituto, no entanto, esbarrou com os interesses das autoridades civis e eclesiásticas locais, que viam a tutela dos padres como útil e necessária para a América Portuguesa ${ }^{30}$. O governo seguinte, do padre Cláudio Aquaviva (1581 -1615), trouxe o problema novamente à pauta de discussões. O Padre Geral empenhava-se em uma campanha de "renovação espiritual” dos membros da Companhia em todas as províncias. Contra o que entendia como envolvimento excessivo dos religiosos em questões políticas locais e um consequente afastamento dos propósitos voltados para a cura da alma, idealizados por Loyola para o Instituto, a alta hierarquia romana acreditava ser importantes reforçar e resgatar a espiritualidade e a identidade jesuíta. Como seu predecessor, o Geral também se opôs à administração temporal dos índios, mas teve de lidar com a resistência da província brasileira em abandoná-la, sob argumentos de que todo o trabalho civilizatório e de catequese se perderia, e os índios acabariam capturados pelos moradores. O caso foi resolvido por uma solução conciliatória, que previa o exercício do poder temporal dentro dos aldeamentos por um índio, mas orientado pelos jesuítas. A dupla tutela, religiosa e temporal, prevaleceu, ainda que mascarada.

O governo romano da Ordem insistiu nos anos seguintes. A mando de Aquaviva, o padre Visitador Manuel de Lima percorreu a província brasileira entre 1607 e 1610 no intuito de promover uma "renovação espiritual" de caráter uniformizador e a retomada de uma identidade jesuítica homogênea afastada dos afazeres temporais. Nesse sentido, o visitador foi contrário à política de autofinanciamento da província, que envolvia, por exemplo, o trato direto dos padres na produção e comercialização dentro e fora do Brasil de produtos agrícolas, como o açúcar, cuja renda sustentava suas atividades religiosas, pedagógicas e missionárias. Os padres não aceitaram facilmente as determinações que Lima trouxe de Roma, e lhe impuseram negociações. Em nome das circunstâncias políticas, econômicas e geográficas específicas que bem conheciam, os religiosos da Companhia no Brasil rejeitaram mais uma vez a tentativa de controle e normatização externa feita pelo governo geral da Ordem. Mais uma vez defendiam sua autonomia na prática das estratégias missionárias desenvolvidas na América Portuguesa $^{31}$.

Em 1660, a questão da autonomização da Companhia no Brasil reapareceu na pauta de discussão da Congregação abreviada da Província, reunida no Colégio da Bahia. Nela, elaborou-se uma lista de demandas ligadas a problemas pelos quais passavam os do Brasil, a ser encaminhada ao comando geral romano. Entre elas, propunham a separação da província brasileira da Assistência de Portugal, além de procurador próprio em Roma atuando junto à representação portuguesa. Justificavam ressaltando a lentidão que a intermediação portuguesa implicava na resolução de questões de interesse dos jesuítas do Brasil, como, por exemplo, a disputa do engenho

\footnotetext{
${ }^{30} \mathrm{~A}$ decisão do padre geral Francisco Borgia de suprimir a jurisdição temporal nos aldeamentos foi rejeitada por uma junta reunida em 1584 no Brasil formada por jesuítas, pelo governador- geral e pelo bispo, que determinou que os missionários deveriam residir nas aldeias e assumir sua gestão temporal e espiritual. Ver Zeron, 2004: 245.

${ }^{31}$ Para Zeron e Charlote, a província brasileira caminhava para uma autonomização missionária crescente. Indício disto seria a permissão concedida pelo governo da Ordem em 1622 para se realizarem visitações feitas por um religioso da própria província e não externo. Ver Castelnau-L’Estoile e Zeron,1999: 357.
} 
de Sergipe do Conde entre os colégios de Santo Antão e o da Bahia. As demandas tratavam também da ampliação da Companhia na província brasileira através do envio de mais missionários e do aumento de admissões permitidas (doze por triênio), inclusive de candidatos de origem indígena. O procurador enviado para encaminhar tais demandas foi o padre Simão de Vasconcelos, acompanhado de um companheiro natural do Brasil, o padre Antônio de Sá, designado para ser o procurador da província em Roma $^{32}$.

As demandas relacionavam-se aos interesses da Ordem em aumentar seu prestígio e influência no Brasil através da ampliação da quantidade de seus membros, o que incluía filhos de homens ilustres da América Portuguesa, mas de sangue indígena.

Fosse admitindo mais naturais da terra, fosse divulgando e glorificando a sua própria atuação em benefício dos habitantes da colônia e do governo português, a Sociedade de Jesus no Brasil punha em prática as estratégias que lhe pareciam mais adequadas para , por um lado, fortalecer laços e alianças políticas que lhe permitisse manter sua política de aldeamentos, muito questionada em certas partes da América Portuguesa, e, por outro, glorificar e defender uma identidade missionária própria e uma atuação mais autônoma junto a seus pares na Europa e ao governo central da Companhia.

Tais práticas e propostas de autonomia da Ordem no Brasil não encontraram eco em Roma. A Cúria Romana jesuítica mais uma vez se mostrou contrária às demandas dos religiosos do Brasil. Praticamente todos os itens da lista encaminhada pelo padre Vasconcelos foram rejeitados e ele foi obrigado a voltar para Lisboa em 1662. Por sua vez, o Padre Geral, João Paulo Oliva, enviou à província um novo visitador, o padre italiano Jacinto de Magistris. O religioso protagonizou mais um episódio que nos indica a continuidade da tensão entre a província e a Cúria por conta da permanência das estratégias próprias de ação encaminhadas pelos do Brasil.

Quando Magistris chegou à Bahia, em junho de 1663, não gostou do que viu: um número excessivo de admissões, demasiados naturais da terra como membros da Companhia, condutas reprováveis para religiosos, o que incluía o envolvimento direto em negociações comerciais. Enviado para fazer valer as prescrições romanas, o visitador foi deposto do cargo e expulso da província brasileira pelos companheiros de ordem em setembro de 1663, três meses após a sua chegada. A iniciativa de retirar Magistris de seu cargo partiu do próprio provincial, o padre José da Costa, que, após votação feita com outros professos mais antigos, inclusive Simão de Vasconcelos, tornou pública a deposição ${ }^{33}$.

O ato extremado, qualificado pelo Padre Geral como sedicioso, precipitado, temerário, injusto, inválido, escandaloso e incoerente ${ }^{34}$, parece ter sido fruto de uma combinação de fatores infeliz: de um lado um visitador pouco hábil nas relações com uma província de características peculiares, muito diferentes das que ele tivera contato no Oriente, e sem disposição para negociações e concessões; do outro, a liderança interna de um grupo, do qual Vasconcelos fazia parte, defensor das estratégias adotadas

\footnotetext{
${ }^{32}$ Camenietzki, 2002: 115-118.

33 Entre os outros votantes estavam os padres Jacinto de Carvalhais, Manuel da Costa, João Luiz, Agostinho Luiz, Barnabé Soares e Luiz Nogueira. Leite, v.7: 38-39.

${ }^{34}$ Ibid.: 39.
} 
no Brasil desde os tempos de Nóbrega. A postura de Magistris mostrou-se problemática exatamente por ir contra o que o grupo entendia como estratégias de adaptação da Companhia no Brasil.

Diferentes de diversos tipos de escritos dos jesuítas voltados, muitas vezes, para a circulação no interior da Ordem, e cujas publicações só ocorreram em épocas bastante posteriores, os textos de Vasconcelos foram impressos no século XVII e, verificadas as datas das licenças e dedicatórias das primeiras edições, bem como a própria biografia do personagem, podemos assumir que foram produzidos pouco tempo antes de virem a público $^{35}$. Assim, nos parece que o padre não apenas desejava divulgar suas ideias, mas preocupou-se em fazê-lo assim que tinha suas obras prontas.

Em consonância à cultura política de sua época, o padre Simão lançou mão do instrumento literário para intervir nos debates e disputas de sua época e sociedade ${ }^{36}$. Ao formular e divulgar em três publicações uma espécie de "memória" historiográfica e hagiográfica da província brasileira, que enfatiza as condições específicas e difíceis da missão, os benefícios oriundos da dupla tutela dos padres sobre os indígenas e é protagonizada por varões santos e virtuosos, Vasconcelos defende, glorifica e justifica uma identidade missionária própria constituída no Brasil, tão exemplar e digna de prestígio quanto a das missões do Oriente $^{37}$. O discurso é coerente com seu posicionamento político dentro da província, alinhado ao grupo hegemônico dentro da Companhia no Brasil em meados do século XVII que, em geral, concordava com a proposta missionária implementada por Manoel da Nóbrega, baseada nos aldeamentos e no autofinanciamento da missão ${ }^{38}$.

Ainda que associadas a campanhas e processos pela beatificação de alguns dos companheiros do Brasil ${ }^{39}$, a Chronica e as "Vidas" possibilitam a análise de discursos "hagiográficos" como estratégia política de legitimação. A santidade, nos escritos de Simão de Vasconcelos, assume também a função de estratégia discursiva para legitimar

\footnotetext{
35 Tivemos acesso à primeira edição da Chronica da Companhia de Jesus do Estado do Brasil na Biblioteca Pública do Estado do Rio de Janeiro, e às primeiras edições das biografias sobre o padre João de Almeida e José de Anchieta na Biblioteca Nacional do Rio de Janeiro (Seção de Obras Raras). Sobre as parcas publicações impressas de jesuítas do Brasil, ver Castelnau-L’Estoile, 2006: 376.

${ }^{36}$ Quanto à noção de “cultura política”, a entendemos como uma pluralidade de fazeres e dizeres imbuídos de interesses sociais diversos e que se constituem como formas variadas de atuação política no século XVII. De imagens, cerimônias e ritos, até sermões e discursos astrológicos, as práticas sócioculturais seiscentistas constituíram, muitas vezes, discursos políticos. Neles podemos identificar interesses, projetos e intenções de diferentes grupos sociais, os quais o autor pode representar direta ou indiretamente. Tais discursos não são elaborados ou direcionados exclusivamente a espaços políticos institucionais, mas ao espaço social como um todo e a todos os seus integrantes. Ver Curto, 1988.

${ }^{37}$ Ver Santos, 2008: 154-157. Segundo Carlos Zeron, em sua análise da Chronica de Vasconcelos, a obra se diferencia e avança em relação a outras obras de jesuítas do Brasil exatamente por tentar pela primeira vez fixar uma determinada “memória histórica” para a Companhia na América Portuguesa. Estendemos essa noção às biografias do padre, pois entendemos que nelas também foi construída uma versão histórica politicamente determinada de alguns fatos selecionados das vidas de João de Almeida e de José de Anchieta com o objetivo de criar uma certa imagem da Ordem no Brasil vinculada aos propósitos defendidos pelo autor. Zeron, 2009: cap.4.

${ }^{38}$ Grupo formado por boa parte dos padres provinciais que sucederam Nóbrega, como Inácio Tolosa, José de Anchieta, Marçal Belliarte, Pero Roiz e Fernão Cardim, e outros bastante atuantes em cargos de liderança na província como Manoel Carneiro e Antonio Vieira. Ver Leite, v.9 e 10.

${ }^{39}$ Como os processos pela canonização de José de Anchieta, iniciado em 1617, e de Inácio de Azevedo e seus 39 companheiros, iniciado em 1623.
} 
a identidade missionária defendida pelo autor. Uma identidade que, lidas com atenção as três obras, é muito mais ampla do que se costuma supor. Baseada inicialmente no controle religioso e civil dos aldeamentos indígenas e na assistência religiosa aos europeus, a atuação dos jesuítas se estendera ao longo do tempo, por conta deste controle indígena e por causa da sustentação material da missão, a questões militares, econômicas, jurídicas e políticas.

Vestidos de "santos", os jesuítas do Brasil, de modo geral, são apresentados como exemplos das virtudes cristãs e, justamente por isso, teriam o direito e o dever moral de orientar os cristãos, índios e portugueses. A “santidade”, portanto, legitima não só a política missionária defendida por Vasconcelos, mas também justifica a identidade missionária defendida por seu grupo, baseada no papel tutelar que os padres da Companhia deveriam desempenhar junto à cristandade do Novo Mundo.

Ao povoar a província brasileira de homens "santos", "mártires” e religiosos exemplares, Vasconcelos granjeava a continuidade da boa vontade do rei e do governo português em relação às atividades da Companhia no Brasil, constantemente criticadas por moradores e autoridades locais. Ao mesmo tempo, Simão respondia às acusações da Cúria romana sobre o afastamento espiritual dos missionários por conta do envolvimento em atividades temporais. Em uma província repleta de exemplos de "santidade”, as opções missionárias, que envolviam atividades seculares, não teriam atingido o compromisso espiritual da missão, e, portanto, não justificavam intervenções externas ou críticas. A excelência dos varões do Brasil, refletida em suas ações, as legitimaria frente a seculares e a religiosos, e justificaria a autonomia da província, defendida pelo grupo de Vasconcelos.

Se a canonização formaliza o culto público e a devoção a um servo de Deus porque através dele Deus se manifesta, Simão de Vasconcelos, frente às críticas internas e externas ao modus procedendi da província brasileira, defendia a "canonização" do que 'São’ João de Almeida e 'São' Anchieta representavam: as opções missionárias dos padres do Brasil, tão excelentes que teriam sido abençoadas e aprovadas pelo próprio Deus ao enviar para esta missão homens "santos".

\section{Referências:}

ARSI - Archivum Romanum Societatis Iesu

BNRJ - Biblioteca Nacional do Rio de Janeiro

Azevedo, João Lúcio de (1992), História de Antonio Vieira, Lisboa: Clássica, 2 v.

Camenietzki, Carlos Ziller (2002), "O Paraíso Proibido. A censura à Chronica de Simão de Vasconcelos em 1663”. Em: Figueroa, Luis Milliones; Ledezma, Domingo (org.), El saber de los jesuítas, historias naturales y el Nuevo Mundo, Madrid: Iberoamericana, pp. 109-134.

Castelnau-L’Estoile, Charlotte de; Zeron, Carlos Alberto de M. R. (1999), “Une mission glorieuse et profitable. Reforme missionaire et économie sucrière dans la province jésuite du Brésil au début du XVIIe. siècle”. Em: Revue de synthèse. Les Jésuites dans le monde moderne. Nouvelles approches, Paris: Centre international de synthèse, n. 2-3, pp. 335-358. 
Castelnau-L'Estoile, Charlotte de (2006), Operários de uma vinha estéril. Os jesuítas e a conversão dos índios no Brasil (1580-1620), Bauru: Edusc.

Certeau, Michel de (1982), A escrita da História, Rio de Janeiro: Forense Universitária.

Curto, Diogo Ramada (1988), O Discurso Político em Portugal (1600-1650). Lisboa: Universidade Aberta.

Delooz, Pierre (1983), “Towards a sociological study of canonized sainthood in the Catholic Church”. Em: Wilson, Stephen, Saints and their cults. Studies in religious sociology, folklore and history, Cambridge: Cambridge University Press, pp.189-216.

Franco Júnior, Hilário (2003). “Apresentação”. Em: Varazze, Jacopo de, Legenda Áurea. Vidas de Santos, São Paulo: Companhia das Letras, pp.11-25.

Gajano, Sofia Boesch (1999), La santità, Roma-Bari: Editori Laterza.

Gotor, Miguel (2004), Chiesa e santità nell'Italia moderna, Roma-Bari: Editori Laterza.

Leite, Antonio Serafim (1938-1950), História da Companhia de Jesus no Brasil, Rio de Janeiro/Lisboa: INL/Portugália, 11 v.

Perrone-Moisés, Beatriz (1992), “Índios livres e índios escravos. Os princípios da legislação indigenista do período colonial (séculos XVI a XVIII)”. Em: Cunha, Manuela Carneiro da (org.), História dos índios no Brasil, São Paulo: Companhia das Letras, pp.115-132.

Santos, Zulmira Coelho dos (2001), "Em busca do paraíso perdido: a Chronica da Companhia de Jesu do Estado do Brasil de Simão de Vasconcelos, S.J.”. Em: Carvalho, José Adriano de Freitas (ed.) Quando os frades faziam História, Porto: Centro universitário de História da espiritualidade, pp.145-178.

(2008), “A literatura 'hagiográfica’ no Brasil do tempo do Pe. António Vieira: da Chronica da Companhia de Jesu do Estado do Brasil e do que obrarão seus filhos nesta parte do Novo Mundo (1663) às biografias devotas de Simão de Vasconcellos”. Românica, Lisboa: Edições Cosmos,v.17, pp.151-166.

Sodano, Giulio (1997), “Il nuovo modello di santità nell'epoca post-tridentina”. Em: Mozzarelli, C.; Zardin, D. I tempi del concilio. Religione, cultura e società nell'Europa tridentina, Roma: Bulzoni, pp.189-205.

Vasconcelos, Simão de (1658), Vida do Padre João de Almeida da Companhia de Jesus, Lisboa: Oficina Craesbeeckiana.

(1663), Chronica da Companhia de Jesus do Estado do Brasil, Lisboa: Henrique Valente de Oliveira, Impressor del Rey N.S.

(1672), Vida do Venerável Padre José de Anchieta da Companhia de Jesus,

Lisboa: João da Costa.

(1953), Vida do Venerável Padre José de Anchieta da Companhia de Jesus, Porto: Lello \& Irmão Editores.

(1977) Crônica da Companhia de Jesus do Estado do Brasil, Petrópolis: Editora Vozes, 2v. 
Von Pastor, Ludwig (1938), The History of the Popes, Londres: Kegan Paul, Trench, Trubner \& Co, v.29.

Woodward, Kenneth L. (1992), A fábrica de santos, São Paulo: Siciliano.

Zeron, Carlos Alberto de M.R. (2004), "Três documentos relacionados à extinção da Companhia de Jesus”. Em: Karnal, Leandro; Neto, José Alves de Freitas (org.), A escrita da memória, São Paulo: Instituto Cultural Banco Santos, pp.225-253.

(2009) Ligne de foi: La Compagnie de Jésus et l'esclavage dans le processus de formation de la societé coloniale en Amérique portugaise, Paris: Honoré Champion. 